\title{
The role of family background on adolescent khat chewing behavior in Jazan Region
}

\author{
Mohamed Salih Mahfouz ${ }^{1 *}$, Rashad Mohammed Alsanosy ${ }^{1,2}$ and Abdelrahim Mutwakel Gaffar ${ }^{1}$
}

\begin{abstract}
Background: Khat is a well-known natural stimulant from the Catha edulis plant and is widely used in certain Red Sea countries, including Yemen and the province of Jazan in Saudi Arabia. Jazan is located in the southwestern part of the Kingdom of Saudi Arabia adjacent to Yemen, where the practice of khat chewing is deeply rooted throughout the entire population. The main objective of this paper was to assess the association between family background, i.e., parent and sibling khat use, and adolescents' khat chewing behavior in Jazan. Other variables were also tested for association, including parents' education levels, family income, and peer influence.
\end{abstract}

Material and methods: A cross-sectional study was conducted with a representative sample $(n=4,100)$ of intermediate and upper secondary school students of Jazan. The participants were selected using a three-stage cluster random sampling. A structured self-administered questionnaire was used for data collection. Descriptive statistics, a chi-squared test, and logistic regression were performed to examine the associations and predictors of khat chewing.

Results: A total of 3,923 students of both genders from 72 intermediate and upper secondary schools in Jazan were involved in this study. Of these participants, $42.8 \%(1,678)$ were from intermediate schools and $43.8 \%(1,717)$ were females. The prevalence of current khat chewing among the students was 20.5\% (95\% confidence interval (Cl) 19.27-21.79) and was significantly higher for males at 33.1\% (95\% Cl 31.16-35.08) than for females, of whom 4.3\% (95\% Cl 3.39-5.31) $(P<0.001)$ chew khat. The multivariate logistic regression analysis suggests that the most important independent predictors of student khat chewing included the students' smoking status (odds ratio (OR) = $14.03, P<0.001)$, a friend using khat $(\mathrm{OR}=5.65, P<0.001)$, a sister using khat $(\mathrm{OR}=2.04, P<0.05)$, a father using khat $(\mathrm{OR}=1.45, P<0.001)$, and a brother using khat $(\mathrm{OR}=1.56, P<0.05)$.

Conclusion: The results highlight the significant impact of peer and familial khat abuse in adolescent khat chewing behavior. The findings suggest that khat control programs need to focus on peers and family members to reduce the prevalence of the habit along with its unfavorable consequences.

Keywords: Khat chewing, Family background, Family attitude

\section{Background}

The consumption of khat is widespread in East Africa and the southern portion of the Arabian Peninsula [1-3]. It is well documented that frequent khat chewing has been associated with unfavorable socioeconomic, public health, and environmental outcomes [4-6].

High-risk adolescent behaviors associated with substance abuse result from multiple causes, often beginning in early childhood, that change with age and are

\footnotetext{
* Correspondence: mm.mahfouz@gmail.com

'Family and Community Medicine Department, Faculty of Medicine, Jazan University, PO Box 2531, Jazan 45142, Saudi Arabia

Full list of author information is available at the end of the article
}

interrelated in complex ways. These causes operate at the levels of socioeconomic status, neighborhood, cultural context, peer influence, teachers' influence and, perhaps most importantly, family influences [7-9].

Three broad categories of family influence have been studied in the literature on adolescent risk-taking: the shape and quality of family interactions, parenting styles and practices, and family modeling and socialization of risky behaviors. Additional family characteristics such as parents' socioeconomic status, maternal age at the birth of the child, ethnicity, and family size and structure play contributing roles as well [7-11].

\section{Biomed Central}


The literature also suggests that family factors and backgrounds play an important role in the development of youth behavior; this family role is very clear in smoking and other substance abuse [12-15]. However, few studies have investigated the role of family factors such as family members' khat chewing habits on adolescent behavior.

Traditional khat use is common in all segments of the population of Jazan province in the southwest area of the Kingdom of Saudi Arabia (KSA) [16,17]. Although khat chewing is illegal in KSA, the practice is widespread and deeply rooted; this may be attributed to Jazan's location adjacent to Yemen, where khat is cultivated and is used by two thirds of Yemenis [3].

The main objective of this study is to evaluate the association between adolescents' khat chewing behavior and characteristics of families in Jazan in the Kingdom of Saudi Arabia. We investigate the family characteristics of parental khat chewing behavior as well as siblings' khat abuse. This study also tests the association between adolescents' khat chewing behavior and parental socioeconomic status, as measured by education levels and family income.

\section{Material and methods \\ Study design}

Our observational cross-sectional survey targeted school students at the intermediate and secondary school levels in Jazan. The inclusion criteria for the study sample were full-time student status, enrollment in one of Jazan's intermediate or secondary schools during the academic year 2011-2012, and age of 13-21 years. General education in KSA is divided into a pre-education stage, where children aged 3-5 years go to kindergarten, and primary education, in which children enter at the age of 6 and remain for 6 years. Intermediate education in Saudi Arabia lasts 3 years, followed by a final 3 years of secondary education.

\section{Study setting}

Jazan (also called Gizan) is one of the 13 provinces of the Kingdom of Saudi Arabia. It is located on the tropical Red Sea coast in southwestern Saudi Arabia and covers an area of $11,671 \mathrm{~km}^{2}$, including some 5,000 villages and towns. Attached to it are 100 islands, including the largest, Farasan. Jazan runs along the Red Sea's coast for almost $300 \mathrm{~km}$ and is highly populated, with 1.5 million residents [18].

\section{Sample size and design}

A representative sample was determined to be 4,100 students, calculated on a large khat survey conducted in 2005 ((prevalence 21.4\%), 95\% confidence interval (CI), marginal error $2 \%$ and non-response rate $10 \%$, design effect 1.5) [17]. The sampling design was a random cluster sampling in three stages based on educational sectors, schools, and classes. Two intermediate schools and two secondary schools for each gender were selected from the nine educational sectors of Jazan. A total of 72 intermediate and secondary schools in Jazan were selected using systematic random sampling. The sampling frames for school selection and the study participants were prepared in consultation with the Ministry of Education, the regional education directorate, and respective schools (to obtain details of classes and number of students in each class level). Probability proportional to size sampling was used to determine the number of students in the selected schools. Systematic random sampling was used to select target students from classes within each school.

\section{Data collection}

A standardized, self-administered questionnaire was used for data collection and was modified to suit schools' student populations. A pilot study was carried out on 160 students to fine-tune questions and to assess the study instrument's reliability before initiating actual data collection. After the pilot study was conducted, minor modifications were made to the original questionnaire. The final questionnaire contained 80 multiplechoice questions organized in four sections. Questions covered demographic data (age, sex) and family characteristics, parents' khat chewing status, parents' attitudes toward their children's khat chewing, khat chewing among siblings, and khat chewing and smoking among peers. The questionnaire asked whether pupils had tried chewing khat at least once in their lifetime, whether they had tried it in the last month, and from where the student had obtained khat during the past month (and if so, how many days they had chewed). The first question was used to evaluate the lifetime prevalence of khat use, whereas the other questions were used to calculate the current prevalence of khat chewing. Permission was obtained from school headmasters and class instructors to collect data during classes. The questionnaires were distributed and collected by health workers from the school health directorate. The anonymity of participants was emphasized, and confidentiality was strictly maintained on all collected questionnaires.

We used the following operational definitions: (a) nonkhat user, students who have never used khat in any form; (b) current prevalence of chewing, the proportion of the study population who were chewing khat within 30 days preceding the study; and (c) ever chewer, an individual who has chewed even if only once in his/her lifetime.

\section{Statistical analysis}

Data entry took place in the Substance Abuse Research Center, Jazan University under the supervision of a data 
analysis specialist. The data entry and analysis were performed using Epi-info (version 3.5.3) and SPSS (version 17) software. To ensure data entry quality, double data entry was performed in eight randomly selected schools and produced good results. Data analysis involved descriptive statistics as well as inferential statistics. Simple tabulation frequencies were used to give a general overview of the data. Khat chewing prevalence was presented using 95\% CIs; chi-squared or Fisher exact tests were performed to determine the associations between individual categorical variables and the outcome (khat chewing). The multivariate analysis involved the spontaneous selection of variables significantly associated with khat chewing by a backward stepwise technique fitted in a multivariate logistic regression model. The final model of factors was checked for fitness using the Hosmer-Lemeshow goodness of fit test. A final regression model was also analyzed for all possible two-way interactions and revealed no significant interaction in the final model. All statistical analyses were performed at the $95 \%$ confidence level.

\section{Ethical issues}

The study proposal and instruments were approved by Jazan University's review board, and voluntary informed oral consent was obtained from each student enrolled in the study.

\section{Results}

The response rate for distributed questionnaires was 95.68\% (3,923 from the target of 4,100 students). The response rates for answering particular questionnaire questions varied, as some students left out some items. The mean age of the participants was 15 years old $(\mathrm{SD}=2.01)$. As seen in Table 1, most sampled students (75.1\%) belonged to the age group of 15-19 years. The distribution of students shows that $61.3 \%$ of students were from urban areas and $38.7 \%$ came from rural areas. As planned during sampling, approximately $57.3 \%$ of the students were from upper secondary schools and $42.7 \%$ from intermediate schools. The gender distributions show that $56.3 \%$ of the students were males and $43.7 \%$ were females.

As shown in Table 2, the prevalence of current khat chewing among students was $20.5 \%$ (95\% CI 19.27-21.79) and was significantly higher for males $33.1 \%$ (95\% CI 31.16-35.08) than for females $4.3 \%$ (95\% CI 3.39-5.31) $(P<0.001)$. Ever khat chewer students accounted for $24.2 \%$ (95\% CI 22.9-25.57) of the population sampled, $38.8 \%$ (95\% CI 36.82-40.88) of whom were males, which is a significantly higher percentage than the $5.4 \%$ (95\% CI 4.39-6.53) of ever khat chewers who were females $(P<0.001)$. The current khat chewing prevalence among intermediate schools was $16.2 \%$, which is significantly lower than that at upper secondary schools, where it was $23.7 \%(P<0.001)$. The same indicators were $22.6 \%$ for rural students and $19.2 \%$ for urban students. Ever khat chewing prevalence was found to be $19.9 \%$ in intermediate schools and $27.4 \%$ in secondary schools. Turning to family influences, Figure 1 shows khat chewing habits in students' families; khat chewing lifetime prevalence among fathers, brothers, mothers, and sisters was found to be $35.8 \%$ (95\% CI 34.3-37.2), 33.5\% (95\% CI $32.0-35.0$ ), $3.9 \%$ (95\% CI 3.3-4.6), and $2.4 \%$ (95\% CI $2.0-2.9)$, respectively.

Table 3 provides the percentage of students who chew khat associated with selected family characteristics. From the table, there was no significant variation in khat chewing prevalence among males and females according to parental (both paternal and maternal) education. There was also no significant difference between a student's khat use and the existence of family disputes for both males and females. Family income levels were not associated with khat chewing prevalence among the adolescents.

Table 4 shows family attitudes toward khat use habits for both sexes. For example, 31.9\% of students reported that their fathers agreed with their khat use behavior (there was no significant difference between males and

Table 1 Background characteristics of the study population

\begin{tabular}{|c|c|c|c|c|c|}
\hline \multirow[t]{2}{*}{ Characteristics } & \multicolumn{2}{|c|}{ Intermediate } & \multicolumn{2}{|c|}{ Secondary } & \multirow[t]{2}{*}{ Total } \\
\hline & Male & Female & Male & Female & \\
\hline \multicolumn{6}{|c|}{ Age groups (years) } \\
\hline $10-14$ & 415 (44.6) & $450(56.1)$ & $10(0.8)$ & $27(2.8)$ & $872(22.2)$ \\
\hline 15-19 & $515(55.4)$ & $328(43.9)$ & 1,199 (93.3) & $909(93.8)$ & 2,951 (75.1) \\
\hline $20-21$ & - & - & $76(5.9)$ & $33(4.4)$ & $109(2.8)$ \\
\hline \multicolumn{6}{|l|}{ Mode of living } \\
\hline Rural & $298(32.0)$ & $320(42.8)$ & $543(42.3)$ & $360(37.2)$ & $1,521(38.7)$ \\
\hline Urban & $632(68.0)$ & $428(57.2)$ & $742(57.7)$ & $609(62.8)$ & 2,411 (61.3) \\
\hline \multirow[t]{2}{*}{ Total } & $930(100)$ & $748(100)$ & $1,285(100)$ & $969(100)$ & $3,923(100)$ \\
\hline & \multicolumn{2}{|c|}{$1,678(42.7)$} & \multicolumn{2}{|c|}{ 2,254 (57.3) } & \\
\hline
\end{tabular}


Table 2 Prevalence of khat chewing among students

\begin{tabular}{|c|c|c|c|c|}
\hline \multirow[t]{2}{*}{ Category } & \multicolumn{2}{|c|}{ Current khat chewers } & \multicolumn{2}{|c|}{ Ever khat chewers } \\
\hline & No. (\%) & $95 \% \mathrm{Cl}$ & No. (\%) & $95 \% \mathrm{Cl}$ \\
\hline \multicolumn{5}{|l|}{ Gender } \\
\hline Male & $733(33.1)^{* * *}$ & $31.16-35.08$ & $860(38.8)^{* * *}$ & $36.82-40.88$ \\
\hline Female & $73(4.3)$ & $3.39-5.31$ & $92(5.4)$ & $4.39-6.53$ \\
\hline \multicolumn{5}{|l|}{ School level } \\
\hline Intermediate schools & $272(16.2)^{* *}$ & $14.52-18.05$ & $334(19.9)^{* *}$ & $18.06-21.88$ \\
\hline Secondary schools & $534(23.7)$ & $21.98-25.49$ & $618(27.4)$ & $25.62-29.30$ \\
\hline \multicolumn{5}{|l|}{ Mode of living } \\
\hline Urban & $462(19.2)^{*}$ & $17.62-20.78$ & $551(22.9)^{*}$ & $21.22-24.57$ \\
\hline Rural & $344(22.6)$ & $20.59-24.79$ & $401(26.4)$ & $24.21-28.63$ \\
\hline Total & $806(20.5)$ & $19.27-21.79$ & $952(24.2)$ & $22.9-25.57$ \\
\hline
\end{tabular}

$P$ value indicates an independent statistical testing. ${ }^{*} P<0.05 ;{ }^{*} P<0.01 ;{ }^{* *} P<0.001$.

females). Moreover, $24.0 \%$ of them reported that their mothers approved of their khat chewing behavior. Surprisingly, $38 \%$ of fathers and $36.9 \%$ of mothers did not know about their children's khat use. When students reported with whom they chewed khat, $60.2 \%$ of males said they chewed with friends, while $32.9 \%$ said they chewed with their families (there were significant differences between their responses $(P<0.001)$ ). The table also shows that $39.5 \%$ of adolescents chewed khat for the first time with their friends, while $26.7 \%$ tried khat for the first time alone, with a significant difference occurring between the sexes $(P<0.001)$.

Family variables such as family members' khat use status were found to be highly associated with students' khat use $(P<0.001$ for all). Having many close friends who chew khat or smoke and smoking status of the student himself or herself were also positively associated with a student's khat chewing status. The student's residential patterns are also an important factor that can be associated with khat use $(P<0.05)$. Those who lived with

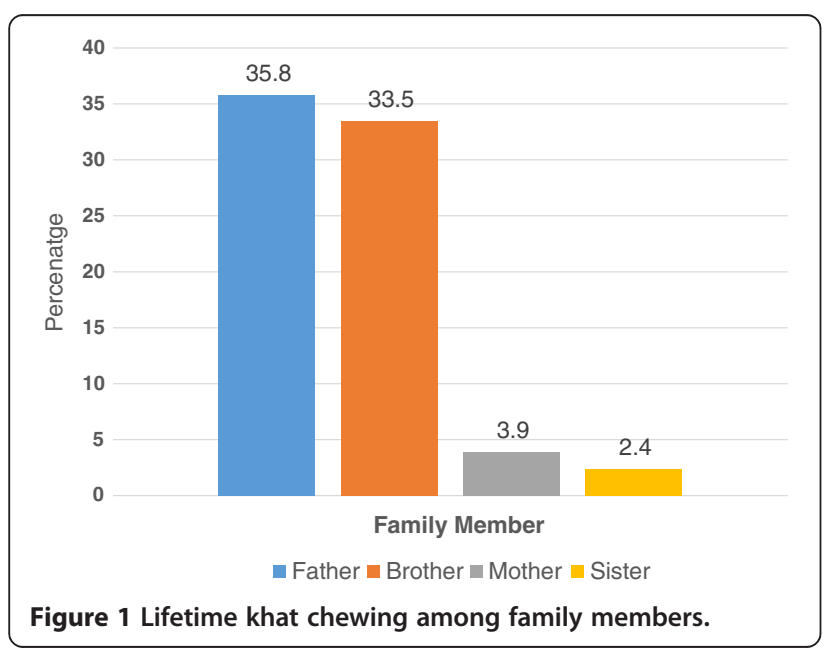

their parents had the lowest khat chewing percentage at $23.4 \%$ compared with the $43.3 \%$ of khat chewers who lived alone (Table 5).

The results of the univariate and multivariate logistic regression analyses for potential risk factors of khat chewing are shown in Table 6. Univariate analysis re-

Table 3 Prevalence of khat chewing according to certain family characteristics

\begin{tabular}{|c|c|c|c|}
\hline \multirow[t]{2}{*}{ Characteristics } & \multicolumn{2}{|c|}{ Gender $^{a}$} & \multirow[t]{2}{*}{ Total } \\
\hline & Male $(n=860)$ & Female $(n=92)$ & \\
\hline \multicolumn{4}{|l|}{ Father's education } \\
\hline Illiterate & $142(35.8)$ & $11(5.1)$ & $153(25.0)$ \\
\hline Primary & $141(42.8)$ & $13(5.3)$ & $159(27.0)$ \\
\hline Intermediate & $126(42.9)$ & $9(4.2)$ & 135 (26.6) \\
\hline Secondary & $102(39.1)$ & $12(4.7)$ & $114(22.1)$ \\
\hline University and above & $171(34.1)$ & $25(5.3)$ & $196(20.2)$ \\
\hline \multicolumn{4}{|l|}{ Mother's education } \\
\hline Illiterate & $252(37.2)$ & $24(4.8)$ & $281(23.5)$ \\
\hline Primary & $163(40.8)$ & $23(6.7)$ & $186(25.1)$ \\
\hline Intermediate & $102(44.7)$ & $13(7.3)$ & $115(28.3)$ \\
\hline Secondary & $63(36.6)$ & $95(3.3)$ & $68(20.9)$ \\
\hline University and above & $115(33.9)$ & $12(3.8)$ & $127(19.5)$ \\
\hline \multicolumn{4}{|l|}{ Family disputes } \\
\hline None & $557(39.2)$ & $30(4.4)$ & $587(27.8)$ \\
\hline Rarely & $143(36.0)$ & $26(5.3)$ & 169 (19.1) \\
\hline Sometimes & $93(41.7)$ & $17(4.2)$ & $110(17.5)$ \\
\hline Always & $21(50.0)$ & $16(19.5)$ & $37(29.8)$ \\
\hline \multicolumn{4}{|l|}{ Family income } \\
\hline Less than $\$ 1,000$ & $160(41.5)$ & $10(3.2)$ & $170(24.4)$ \\
\hline$\$ 1,001-3,000$ & $247(40.2)$ & $22(4.4)$ & $269(24.2)$ \\
\hline More than $\$ 3,000$ & 158 (35.9) & $18(6.3)$ & $176(24.2)$ \\
\hline
\end{tabular}

${ }^{a}$ No significant association was observed. 
Table 4 Family attitude toward khat chewing

\begin{tabular}{|c|c|c|c|c|}
\hline Characteristics & $\begin{array}{c}\text { Male } \\
(n=860)\end{array}$ & $\begin{array}{l}\text { Female } \\
(n=92)\end{array}$ & Total & $P$ value \\
\hline Father's attitude toward khat chewing & & & & $P>0.05$ \\
\hline Agree & $255(32.2)$ & $22(28.2)$ & 277 (31.9) & \\
\hline Disagree & $183(23.1)$ & $20(25.6)$ & $203(23.4)$ & \\
\hline Do not know & $299(37.8)$ & $31(39.7)$ & $330(38.0)$ & \\
\hline Father dead & $54(6.8)$ & $5(6.4)$ & $59(6.8)$ & \\
\hline Mother's attitude toward khat chewing & & & & $P>0.05$ \\
\hline Agree & $185(23.5)$ & $22(28.2)$ & $207(24.0)$ & \\
\hline Disagree & $291(37.0)$ & $26(33.3)$ & $317(36.7)$ & \\
\hline Do not know & $292(37.2)$ & $27(34.6)$ & $319(36.9)$ & \\
\hline Mother dead & $18(2.3)$ & $3(3.8)$ & $21(2.4)$ & \\
\hline \multicolumn{5}{|l|}{ With whom do you chew khat } \\
\hline Family & $45(5.8)$ & $23(32.9)$ & $68(8.1)$ & $P<0.001$ \\
\hline Relatives & $152(19.7)$ & $13(18.6)$ & $165(19.6)$ & \\
\hline Friends & $464(60.2)$ & $16(22.9)$ & $480(57.1)$ & \\
\hline Alone & $110(14.3)$ & $18(25.7)$ & $128(15.2)$ & \\
\hline With whom did you chew khat for the first time & & & & $P<0.001$ \\
\hline Father/mother & $90(11.5)$ & $11(15.9)$ & $101(11.9)$ & \\
\hline Relative & $163(20.9)$ & $23(33.3)$ & $186(21.9)$ & \\
\hline Friends & $322(41.2)$ & $14(20.3)$ & $336(39.5)$ & \\
\hline Alone & $206(26.4)$ & $21(30.4)$ & $227(26.7)$ & \\
\hline
\end{tabular}

vealed that family members' khat use status, having close friends who chew khat or smoke, and student smoking status were associated with a significant risk of khat chewing $(P<0.001$ for all). The multivariate logistic regression analysis suggests that the most important independent predictors of khat chewing among the students in our sample were students' smoking status (odds ratio $(\mathrm{OR})=14.03, P<0.001)$, friends using khat $(\mathrm{OR}=5.652$, $P<0.001)$, sister's use of khat $(\mathrm{OR}=2.04, P<0.05)$, father's use of khat $(\mathrm{OR}=1.45, P<0.001)$, and brother's use of khat $(\mathrm{OR}=1.56, P<0.05)$.

\section{Discussion}

The objective of this study was to evaluate the role of family factors like parental education levels, family members' khat use, and other factors on the khat chewing status of adolescents in the province of Jazan in KSA.

The study revealed that a significant proportion of Jazan students $(20.5 \%)$ chew khat $33.1 \%$ for males and $4.3 \%$ for females). The prevalence of khat chewing among students is less than that observed among the general population in Jazan, Yemen, Ethiopia, and Somalia $[19,20]$. Lifetime khat chewing prevalence in the current study was $24.2 \%$ (males $38.8 \%$, females $5.4 \%$ ), which is approximately similar to that reported in Jazan previously $[16,17]$. The use of khat (current and lifetime) was significantly higher among males, which also parallels results reported previously in Jazan and Ethiopia $[16,17]$.

Unlike the bulk of the tobacco literature where the association between socioeconomic status and smoking is well established [21-23], parental education levels, occupation, and family income levels have no significant association with adolescents' khat chewing behavior. This is similar to findings on the roles of family backgrounds on cigarette smoking among adolescent school children in Slovakia, where parent educational level and employment status were not statistically associated with students' smoking status [24].

Social acceptability of khat chewing and socialization of this habit increase the likelihood of adolescents adopting the behavior. Less than a quarter of the study population reported that their parents disagree with their use of khat. This attitude is further supported by the socialization of this habit, as more than half of the female students and a quarter of the male students chew khat with family members and relatives. This social acceptability is more pronounced when we consider 
Table 5 Comparison of khat chewers versus non-chewers with regard to certain variables

\begin{tabular}{|c|c|c|c|}
\hline \multirow[t]{2}{*}{ Variables } & \multicolumn{2}{|c|}{ Khat chewing status } & \multirow[t]{2}{*}{$P$ value } \\
\hline & Khat chewers & Non-chewers & \\
\hline Father using khat $(n=3,557)$ & & & $P<0.001$ \\
\hline Yes & $461(32.8)$ & $945(67.2)$ & \\
\hline No & $397(18.5)$ & $1,754(81.5)$ & \\
\hline Mother using khat $(n=3,699)$ & & & $P<0.001$ \\
\hline Yes & $62(40.3)$ & $92(59.7)$ & \\
\hline No & $821(23.2)$ & $2,724(76.8)$ & \\
\hline Brother using khat $(n=3,635)$ & & & $P<0.001$ \\
\hline Yes & $487(37.9)$ & $830(63.0)$ & \\
\hline No & $372(16.0)$ & $2,776(84.0)$ & \\
\hline Sister using khat $(n=3,682)$ & & & $P<0.001$ \\
\hline Yes & $48(50.5)$ & $47(49.5)$ & \\
\hline No & $829(23.1)$ & $2,758(76.9)$ & \\
\hline Student smoking status $(n=3,628)$ & & & $P<0.001$ \\
\hline Yes & $489(54.3)$ & $138(5.1)$ & \\
\hline No & $411(45.7)$ & $2,590(94.9)$ & \\
\hline Friends smoking $(n=3,667)$ & & & $P<0.001$ \\
\hline Yes & $592(66.0)$ & $689(24.9)$ & \\
\hline No & $305(34.0)$ & $2,083(75.1)$ & \\
\hline Friend using khat $(n=3,761)$ & & & $P<0.001$ \\
\hline Yes & $746(81.2)$ & $762(26.8)$ & \\
\hline No & $173(18.8)$ & $2,080(73.2)$ & \\
\hline Residence pattern $(n=3,894)$ & & & $P<0.05$ \\
\hline Parents & $815(23.4)$ & $2,670(76.6)$ & \\
\hline Father & $31(36.5)$ & $54(63.5)$ & \\
\hline Mother & $63(26.8)$ & $172(73.2)$ & \\
\hline Relatives & $19(32.2)$ & $40(67.8)$ & \\
\hline Alone & $13(43.3)$ & $17(56.7)$ & \\
\hline
\end{tabular}

circumstances in which the adolescent chewed khat for the first time. Again, about half of the female students and a third of the male students chewed khat for the first time with family members and relatives. In general, the majority of adolescents reported that they use khat with someone else rather than chewing alone. This finding is consistent with the broader literature on adolescent substance use in general [25] and adolescent smoking in particular [26] - adolescents who receive low levels of parental behavioral control and acceptance show the greatest prevalence of substance abuse [9]. It is equally important that $38.0 \%$ of students said that their fathers were unaware of their khat use, compared with $36.9 \%$ who reported that their mothers were unaware. These figures testify to the significant number of adolescents in Jazan who chew khat without their parents' knowledge.
Residence patterns also appear to impact khat chewing status. This study suggested that adolescents living with their parents have the lowest percentage of khat chewing at $23.4 \%$ compared with the $43.3 \%$ of khat chewers who live alone. Similar findings with alcohol use have been reported in the USA [8].

Knowledge on risk factors and predictors is crucial to designing prevention programs that target high-risk groups of adolescents. Family members' khat chewing status, having close friends who chew khat or smoke, and student smoking status were highly associated with a significant risk of khat chewing. The associations between friends' and adolescents' substance abuse behaviors have been deeply investigated in the literature [27-31]. Our univariate analysis documented the strong impact of peers on khat chewing status. Regarding the impact of family khat use, the most 
Table 6 Univariate and multivariate logistic regression analyses for family khat use-related factors among study participants

\begin{tabular}{|c|c|c|c|c|c|c|}
\hline \multirow[t]{2}{*}{ Category } & \multicolumn{3}{|c|}{ Univariate } & \multicolumn{3}{|c|}{ Multivariate $^{a}$} \\
\hline & OR & $95 \% \mathrm{Cl}$ & $P$ value & OR & $95 \% \mathrm{Cl}$ & $P$ value \\
\hline \multicolumn{7}{|c|}{ Mother using khat } \\
\hline No (ref.) & 1 & & & & & \\
\hline Yes & 2.24 & $1.61-3.11$ & $P<0.001$ & & & \\
\hline \multicolumn{7}{|c|}{ Father using khat } \\
\hline No (ref.) & 1 & & & 1 & & \\
\hline Yes & 2.15 & $1.84-2.51$ & $P<0.001$ & 1.45 & $1.16-1.82$ & $P<0.001$ \\
\hline \multicolumn{7}{|c|}{ Brother using khat } \\
\hline No (ref.) & 1 & & & 1 & & \\
\hline Yes & 3.07 & $2.62-3.59$ & $P<0.001$ & 1.56 & $1.27-2.00$ & $P<0.05$ \\
\hline \multicolumn{7}{|c|}{ Sister using khat } \\
\hline No (ref.) & 1 & & & 1 & & \\
\hline Yes & 3.30 & $2.52-5.11$ & $P<0.001$ & 2.041 & $1.11-3.74$ & $P<0.05$ \\
\hline \multicolumn{7}{|c|}{ Student smoking status } \\
\hline No (ref.) & 1 & & & 1 & & \\
\hline Yes & 22.33 & $17.99-27.70$ & $P<0.001$ & 14.03 & $10.76-18.30$ & $P<0.001$ \\
\hline \multicolumn{7}{|c|}{ Friends smoking } \\
\hline No (ref.) & 1 & & & 1 & & \\
\hline Yes & 5.87 & $4.99-6.91$ & $P<0.001$ & 1.44 & $1.08-1.94$ & $P<0.05$ \\
\hline \multicolumn{7}{|c|}{ Friend using khat } \\
\hline No (ref.) & 1 & & & 1 & & \\
\hline Yes & 11.77 & $9.78-14.16$ & $P<0.001$ & 5.65 & $3.92-8.14$ & $P<0.001$ \\
\hline
\end{tabular}

${ }^{\mathrm{a}}$ Hosmer-Lemeshow goodness of fit test $X^{2}=7.01, p=0.43$.

important independent predictors of khat chewing among students in our sample were a sister using khat, a father using khat, and a brother using khat. The substance abuse literature suggests that parental abuse is an influential factor affecting children's substance abuse status. Other studies have found both parental smoking behavior and parents' attitudes toward their children's smoking are influential factors for adolescent smoking [32-34].

The main strength of this study lies in the fact that it is the first study to investigate the role of family characteristics in khat chewing in the Jazan region. However, some significant limitations should be mentioned. The obvious limitations include the fact that the questionnaire given to students at the intermediate level was self-administered. Data collected based on student self-reports may be subject to recall bias and to under-reporting of khat use due to a social desirability bias. Additionally, the cross-sectional study design may not be suitable for assessing directional and causal relationships of the studied variables with khat chewing behavior. Furthermore, the reporting of family khat use was based on lifetime khat chewing only. Finally, the study assessed only associations between family variables and khat use, with no emphasis given to khat use patterns and excessive use. In summary, our study calls for more in-depth research on the relationship between family khat chewing and adolescent khat chewing behavior.

\section{Conclusion}

The study results highlight the significant impact of peers, fathers, sisters, and brothers on adolescent risktaking behaviors and the need to strengthen the family's role in prevention. Khat is a socially acceptable habit in Jazan, and our findings suggest that khat control program efforts need to focus on peers and family members to reduce the prevalence of the habit and its unfavorable consequences. Peer impact is higher among male users than among females. With both genders, these results emphasize the importance of peer education interventions as one strategy for changing social norms in the population. 


\section{Competing interests}

The authors declare that they have no competing interests.

\section{Authors' contributions}

MSM, RMA, and AMG prepared the project proposal and designed the research paper. MSM and AMG performed data analysis. MSM, AMG, and RMA wrote the manuscript and provided significant input on the manuscript. All authors read and approved the final manuscript.

\section{Acknowledgments}

We would like to thank Dr. Anwar Makeen for his valuable comments and suggestions in the early work. We also thank Dr. Anwar Alahmar and Dr. Abdulwahab Ageeli from SARC for their efforts in supervising the data collection phase. We appreciate the efforts of the education directorate in Jazan Region, administrative staff, teachers, and school health professionals for coordination and help with data collection. This work was funded by the Substance Abuse Research Center (SARC), Jazan University, Saudi Arabia under grant project no. 100

\section{Author details}

${ }^{1}$ Family and Community Medicine Department, Faculty of Medicine, Jazan University, PO Box 2531, Jazan 45142, Saudi Arabia. ² Substance Abuse Research Center (SARC), Jazan University, Jazan 45142, Saudi Arabia.

Received: 10 December 2012 Accepted: 6 May 2013

Published: 20 May 2013

\section{References}

1. Krikorian A: Khat and its use: a historical perspective. J Ethnopharmacol 1984, 12:115-178.

2. Ageely HM: Health and socio-economic hazards associated with khat consumption. J Fam Community Med 2008, 15(1):3-11.

3. Rahim BEA, Yagoub U, Mahfouz MS, Solan YMH, Alsanosi R: Abuse of selected psychoactive stimulants: overview and future research trends. Life Sci J 2012, 9(4):2295-2308.

4. Ali AA, Al-Sharabi AK, Aguirre JM, Nahas R: A study of 342 oral keratotic white lesions induced by qat chewing among 2500 Yemeni. J Oral Pathol Med 2004, 33:368-372

5. Kassim S, Croucher R: Khat chewing amongst UK resident male Yemeni adults: an exploratory study. Int Dent J 2006, 56(2):97-101.

6. Gelaye B, Philpart M, Goshu M, Berhane Y, Fitzpatrick AL, Williams MA: Anger expression, negative life events and violent behaviour among male college students in Ethiopia. Scand J Public Health 2008, 2006(36):538-545.

7. Reiss D, Leve LD: Genetic expression outside the skin: clues to mechanisms of genotype $x$ environment interaction. Dev Psychopathol 2007, 19:1005-1027.

8. Johnson V, Pandina R: Effects of the family environment on adolescent substance use, delinquency, and coping styles. Am J Drug Alcohol Abuse 1991, 17:71-88.

9. Jackson C, Bee-Gates D, Henriksen L: Authoritative parenting, child competencies, and initiation of cigarette smoking. Health Educ Q 1994 21:103-116.

10. Hill KG, Hawkins JD, Catalano RF, Abbott RD, Guo J: Family influences on the risk of daily smoking initiation. $J$ Adolesc Health 2005, 37:202-210.

11. Kandel DB, Wu P: The contributions of mothers and fathers to the intergenerational transmission of cigarette smoking adolescence. $J$ Res Adolesc 1995, 5(2):225-252.

12. Forrester K, Biglan A, Severson HH, Smolkowski K: Predictors of smoking onset over two years. Nicotine Tob Res 2007, 9:1259-1267.

13. Fidler JA, West R, van Jaarsveld CH, Jarvis MJ, Wardle J: Smoking status of step-parents as a risk factor for smoking in adolescence. Addiction 2008, 103:496-501.

14. Madarasova Geckova A, Stewart R, van Dijk JP, Orosova O, Groothoff JW, Post D: Influence of socio-economic status, parents and peers on smoking behaviour of adolescents. Eur Addict Res 2005, 11:204-209.

15. Komro KA, McCarty MC, Forster JL, Blaine TM, Chen V: Parental, family, and home characteristics associated with cigarette smoking among adolescents. Am J Health Promot 2003, 17:291-299.

16. Alsanosi R, Bani I, Ageely H, Milaat W, Elnajjar M, Makeen A, Yagob U: Socio-medical problem of the habituation of Khat chewing in Jazan region in Southern Saudi Arabia. Eur J Sci Res 2011, 63(No.1):122-133.
17. Ageely HM: Prevalence of Khat chewing in college and secondary (high) school students of Jazan region, Saudi Arabia. Harm Reduction J 2009, 6:11.

18. Department of Statistics and Information, KSA: 2010-1431 Population census preliminary results. 2010 [http://www.cdsi.gov.sa/]

19. Laswar AKN, Darwish H: Prevalence of cigarette smoking and khat chewing among Adin University Medical Students and their relationship to PB and body mass index. Saudi J Kidney Dis Transp/ 2009, 20(5):862-866.

20. Zein Z: Polydrug abuse among Ethiopian university students with particular reference to khat (Catha edulis). J Trop Med Hyg 1988, 91(2):71-75.

21. Schaap MM, Kunst AE: Monitoring of socio-economic inequalities in smoking: learning from the experiences of recent scientific studies. Public Health 2009, 123:103-109.

22. Huurre $\mathrm{T}$, Aro H, Rahkonen O: Well-being and health behaviour by parental socioeconomic status: a follow-up study of adolescents aged 16 until age 32 years. Soc Psychiatry Psychiatr Epidemiol 2003, 38:249-255.

23. Harwood GA, Salsberry P, Ferketich AK, Wewers AE: Cigarette smoking, socioeconomic status, and psychosocial factors: examining a conceptual framework. Public Health Nurs 2007, 24:361-371.

24. Baška T, Warren CW, Hudečková H, Ochaba R, Stastný P, Lea $V$, Lee J: The role of family background on cigarette smoking among adolescent school children in Slovakia: findings from the 2007 Slovakia Global Youth Tobacco Survey. Int J Public Health 2010, 55(6):591-597.

25. Hawkins J, Catalano R, Miller J: Risk and protective factors for alcohol and other drug problems in adolescence and early adulthood: implications for substance abuse prevention. Psychol Bull 1992, 112:64-105.

26. Chassin L, Presson CC, Rose J, Sherman SJ, Davis MJ, Gonzalez JL: Parenting style and smoking-specific parenting practices as predictors of adolescent smoking onset. J Pediatr Psychol 2005, 30(4):333-344.

27. Mercken L, Candel M, Willems P, de Vries H: Disentangling social selection and social influence effects on adolescent smoking: the importance of reciprocity in friendships. Addiction 2007, 102:1483-1492.

28. Lundborg P: Having the wrong friends? Peer effects in adolescent substance use. J Health Econ 2006, 25:214-233.

29. Schofield PE, Pattison PE, Hill DJ, Borland R: The influence of group identification on the adoption of peer group smoking norms. Psychol Health 2001, 16:1-16.

30. Simons-Morton B, Chen RS: Over time relationships between early adolescent and peer substance use. Addict Behav 2006, 31:1211-1223.

31. Duan L, Chou CP, Andreeva VA, Pentz MA: Trajectories of peer social influences as long-term predictors of drug use from early through late adolescence. J Youth Adolescence 2009, 38:454-465.

32. Szabo E, White V, Hayman J: Can home smoking restrictions influence adolescents' smoking behaviors if their parents and friends smoke? Addict Behav 2006, 31:2298-2303.

33. Albers $A B$, Biener $L$, Siegel $M$, Cheng DM, Rigotti N: Household smoking bans and adolescent antismoking attitudes and smoking initiation: findings from a longitudinal study of a Massachusetts youth cohort. Am J Public Health 2008, 98:1886-1893.

34. Harakeh Z, Scholte RHJ, Vermulst AA, de Vries H, Engels R: Parental factors and adolescents' smoking behavior: an extension of the theory of planned behavior. Prev Med 2004, 39:951-961.

\section{doi:10.1186/1744-859X-12-16}

Cite this article as: Mahfouz et al:: The role of family background on adolescent khat chewing behavior in Jazan Region. Annals of General Psychiatry 2013 12:16 